\title{
Anchoring Sustainable Urbanism as Future of cities
}

\author{
Ar. Sangeeta S., Ar. Sreesha S. Bhat
}

\begin{abstract}
The study aims to understand the concept of Sustainable Urbanism and its scope in Indian city planning. Study focuses various objectives such as impact of urbanization at global and national level, concepts of livability and sustainability globally, planning principles considered by urban planners to achieve these in cities, and critically analyzing them with current trend of Urban Planning Policy - making in India. This paper broadly covers the research questions and explains what is meant by sustainable urbanism, what sustainability in terms of City planning is and what different parameters could be to achieve sustainability at city level.
\end{abstract}

Keywords:- Sustainable Urbanism, City planning, Urban Development

\section{INTRODUCTION}

Last two decades, India witnessed a dramatic change in Urbanization creating a huge challenge for Planners in designing, redesigning and retrofitting the existing urban fabric of the cities. With increase in population and density, urban cities face many challenges. As per the Assessment of Air Pollution in Indian Cities, report by Greenpeace Organization, pollution is a national problem which is killing 1.2 million Indians per year costing the economy of estimated 3\% of GDP. Pollution is only one among the many challenges which an Indian city faces. Quality of Life is one of the basic needs of humankind. Adequate food supply, clean air, water supply, proper drainage, sanitation facility, solid waste management, power supply, Better Connectivity, Provision of Public Realm are some of the basic amenities a city ought to provide, which cannot be denied from general public. Planning basically deals with gratification of future needs through appropriate allocation of resources. Recently, all the tiers of Planning and Development Authorities; Central level, State level and District/ ULB's have started focusing their development plans and policies considering "Sustainability" as a key parameter. Sustainable Urbanism is a recent terminology flourished in the streams of Planning, Urban designing and Policy making. Various National Schemes and Building level initiatives ranging from Smart city Mission, JNNURM, AMRUT Yojana and Self-sustainable Villages to Green Buildings and Vertical Gardens clearly indicates the future direction of City Planning. This paradigm shift in the scope of Indian Urban design and development is far beyond Architecture or City Planning. Study focuses on Policies and Guidelines taken by the Government in the last two decades concerning to City Level development. Building

Revised Manuscript Received on April 12, 2019.

Ar. Sangeeta S, Assistant Professor, Nitte Institute of Architecture, Paneer Campus, Deralakatte, Mangalore, Karnataka, India. (sangeeta@nitte.edu.in)

Ar. Sreesha S. Bhat, Assistant Professor, Nitte Institute of Architecture, Paneer Campus, Deralakatte, Mangalore, Karnataka, India. (sreeshabhat@nitte.edu.in) level policies such as ECBC Compliances, GRIHA, LEED etc has not been considered.

\section{GLOBAL SCENARIO: LIVABILITY, SUSTAINABILITY AND NEW URBANISM}

With the increase in population and density, cities started growing compact with poor living conditions. Demand for Livable spaces and Sustainable living increased. Concept of Livability started by mid-1950's where Vancouver was considered to be one of the most Livable city. Vancouverism is characterized by its large residential population with mixed-use developments living in the city center. Buildings with commercial base and high-rise residences over them, mass public transit system, green park spaces were some of the significances. Many Urban planners tried to take inspiration from this Livable City Model and implement on their cities.

"Sustainability" was first used in 1972 in a British book "Blueprint for Survival", followed by that United Nations in 1978 used it in documents. From 1978, many national and international summits focused on Sustainable development as Eco development. Although concept of sustainability flourished from last many decades, it lacked comprehension of Urban Design. Essays of Doughlas Farr (2008) mentions creating sustainable neighborhood; car free areas, walkable neighborhood and universal accessibility by integrating transportation and land use. He further mentions about increasing sustainability through density and linking Human to Nature by providing walk-to open spaces, neighborhood storm water systems, waste management and food production.

In 1980's, a new Urban Design Movement "New Urbanism" flourished in the Unites States. New Urbanism supports regional contextual planning, increased density, safe streets, walkability, better connectivity, smart transportation, enhanced quality of life, diversity, historic preservation and sustainable approach of using natural and energy efficient technologies. These ideas can be broadly classified to two concepts: Building sense of community and Developing Ecological practices

Sustainable Urbanism is a recent contribution to urban planning where both study of cities and practices to build them sustainably for future is focused. It promotes long term viability by reducing consumption, waste and harmful impacts on people and place, and enhancing overall wellbeing. Creative ideas such as Green urbanism and Ecological urbanism emphasis more on Natural Environment and ecosystem than Economic and Social Aspect in a particular city. 
UN General Assembly Summit, 2015 formulated seventeen Sustainable Development Goals (SDG's) and 169 targets for 2030 which is adopted by its 193 Member states. India is strongly committed to the 2030 Agenda. UN Environment supports member nations to achieve Sustainable Development Goals (SDG's) for Cities with specific focus on providing access to:

- Housing and Basic Services

- Sustainable Transport System

- Sustainable Urbanization

- Access to Public spaces

- Sustainable buildings

- Per Capita environmental impact

- Policies towards climate change

- Resource Efficiency

\section{URBANIZATION IN INDIA}

The main factors for Urbanization are migration and expansion of cities. Economic opportunities of urban areas attract people from smaller towns to larger cities. According to McKinsey report,

- India's urban population will grow from 410 million in 2014 to 814 million by 2050 .

- By 2025, 46\% of citizens will live in cities with million plus population.

- By 2030, number of cities with million plus population will grow from 42 in 2010 to 68 .

With urbanization, Indian economy is extremely dependent on investments made in housing, institutions, transportation and infrastructure, basic services such as water, sanitation, electricity and other forms of urban management.

\section{FRAMEWORK OF POLICIES IN INDIA}

In India, planning is done at multi-level; Central tier, State tier and Local tier. After 74th Constitutional Amendment Act, when Decentralisation of Planning organisation was encouraged, local authorities or Urban Local Bodies (ULB's) were given authority to take decisions and implement them in their own areas for development. Paradigm shift from Top - Down approach to Bottom - Up approach gave rise to a new dimension of micro-level planning.

Currently, two types of planning systems are laid out for Spatial Planning:

- National Institution for Transforming India (NITI Ayog), which aims to target cooperation and active participation in the economic policy-making process led by the State governments of India. NITI Ayog has undertaken a "mapping of schemes" and identified Ministries to target for so as to achieve these Sustainable Development Goals.

- Ministry of Urban Development (MoUD), Ministry of Housing and Urban Poverty Alleviation (MoHPA), and the Town and Country Planning Organization (TCPO). These are Central government authorities which facilitate and support the nationwide urban and regional development planning.
In last few decades, most of the funding for a City development by Central Government focuses to achieve overall sustainable development of cities in different sectors. India's National Development Goaland its policy initiatives for Inclusive development Sab ka Saath, Sab ka Vikaas, converge with Sustainable Development Goals (SDG's). Some of them are:

\section{Jawaharlal Nehru National Urban Renewal Mission (JNNURM) 2005}

This mission, started in 2005 envisioned city modernization within span of seven years. Underdeveloped cities were targeted and focused on improving social and economic infrastructure by providing basic amenities such as water, sanitation, solid waste management, connectivity and redevelopment of old part of the cities. JNNURM had sub-mission schemes under it namely,

- Basic Services for Urban Poor (BSUP)

- Urban Infrastructure Development Scheme for Small and Medium Town (UIDSSMT)

- Integrated Housing and Slum Development Programme (IHSDP)

\section{National Action Plan on Climate Change (NAPCC) 2008:}

National action plan on climate change identifies measures that promote India's development. By releasing NAPCC, India has shown its commitment to address climate change issues and also sent a progressive message globally about the government's concern to address the climate change issue through determined action. It broadly aims to make sustainable cities through improvements in energy efficiency in buildings, management of solid waste $\&$ shift to public transport through its eight missions.

1. Jawaharlal Nehru National Solar Mission (JNNSM) 2010: India, being in Tropical region receives quantum of solar light, potential of this renewable future source of energy is promoted by Government of India and State government by setting up an enabling environment for solar technology penetration in the country both at a centralized and decentralized level.

2. National Mission for Enhanced Energy Efficiency (NMEEE): This mission focuses on facilitating energy intensive industries to reduce their energy footprint.

Mission specifies four initiatives under it:

- Performance Achieve and Trade (PAT): Industries are given energy reduction target. On achieving the target, Energy Saving Certificates are be given to them which can be traded.

- Market Transformation and Energy efficiency (MTEE). To encourage Innovative Business Models for promoting Energy efficient equipment and appliances.

- Energy Efficiency Financing Platform (EEFP): Finance institutions are targeted to invest and support energy efficient initiatives. 
- Framework for Energy Efficiency Economic Development: To ensure support to financial institutions and investors offering loans for energy efficient projects by providing risk cover and promoting equity finance.

PAT is implemented in four phases. As per the 2018 status report by Bureau of Energy Efficiency, after the first phase (2012-15), about 400 large industries participated and took steps to improve Energy efficiency and as a result energy worth Rs 9500 crore was saved annually.

3. National Water Mission: Objective of the Mission is to conserve water, minimize wastage and ensure equitable distribution through integrated water resources management. This mission is backed by Ministry of Water Resources, River Development and Ganga Rejuvenation.

4. National Mission for Sustaining Himalayan Ecosystem (NMSHE) 2014: Since significant proportion of India's population depends on Himalayan range for sustenance, mission contributes to the sustainable development of the country by enhancing the understanding of climate change, its likely impacts and adaptation actions required for the Himalayas.

5. National Mission on Sustainable Habitat 2011: Mission aims to make cities sustainable through improvements in energy efficiency in buildings, management of solid waste and shift to public transport. The Ministry of Housing and Urban Affairs backs the mission.

6. National mission for Green India: This National Scheme aims at protecting, restoring and enhancing India's diminishing forest cover and responding to climate change by a combination of adaptation and mitigation measures. Ministry of Environment and Forests backs this mission.

7. National Mission for Sustainable Agriculture: Mission focuses in enhancing agricultural productivity, integrated farming, water use efficiency, soil health management and synergizing resource conservation.

8. National mission on Strategic knowledge of climate change: Mission pursues capacity building by creating a dynamic and vibrant knowledge system. Department of Science and Technology drives the mission.

Ministries with lead responsibility for each of the missions are directed to develop objectives, implementation strategies, timelines, and monitoring and evaluation criteria to be submitted to the Prime Minister's Council on Climate Change. The Council is also be responsible for periodically reviewing and reporting on each mission's progress. To quantify progress, appropriate indicators and methodologies will be developed to assess both avoided emissions and adaptation benefits.

Urban and Regional Development Plans Formulation and Implementation (URDPFI) Guidelines, 2014

This modified version of 1996 URDFI Guideline has been framed to incorporate provisions of legal and policy guidelines to guide Urbanization. This was a major breakthrough for Indian Urban Planning as for the first time it discussed regional development, inclusive planning, sustainable habitat, transport integration at planning stage and governance reforms.

State Town and Country Planning, Urban Development Authorities, Urban Local Bodies and Schools of Planning will help State Government to adopt these guidelines by preparing Masterplans for cities.

Accordingly, for overall recommendations for future actions,

Urban and Regional Planning system has been divided unde r two heads,

a) Core Area Planning and

b) Specific and Investment Planning.

The core area planning comprises of set of four interdependent plans:

- Perspective Plan, a long term plan with a vision and policy

- Regional Plan, a sustainability based long term plan

- Development Plan, a long term comprehensive settlement plan

- Local Area Plan, a short term plan within the framework of Development Plan

Specific and Investment Planning comprises a set of three plans:

- Special Purpose Plan, plans for special areas within the framework of Development Plan.

- Annual Plan, plans to translate the physical and fiscal resource requirement of Development / Local Areas Plan

- Project Research plans, focusing on items of execution

URDFI provides guidelines for Special Area Planning Regions such as Eco sensitive regions, Coastal regions and Socio-economic sensitive regions. Guidelines for Sustainability focusses on Energy efficiency, sustainable planning, environmental guidelines for industries, rain water harvesting, green buildings, urban water bodies, green cities and natural habitat, indicators to measure city bio diversity index, etc.

URDPI Guidelines remarks planning processes suggested in the planning system, resource mobilization for plan implementation, institutional reforms, approaches and strategies for regional and urban planning, planning approach for Green cities, Compact cities (Transit Oriented Development, TOD) and SMART cities.

\section{SBA: Swachh Bharat Abhiyan (Clean India Mission) 2014}

The mission aims to clean up streets, road and infrastructure of India's cities, towns and village. Objective of the mission was to eliminate open defecation through construction of toilets at household level and at community level as well as to have an accountable mechanism of monitoring toilet use. Swacch Bharath Abhiyan (Rural) operates under Ministry of Drinking Water and Sanitation. Swacch Bharath Abhiyan (Urban) operates under Ministry of Housing and Urban Affairs.

Published By:

Blue Eyes Intelligence Engineering $\&$ Sciences Publication 
Atal Mission for Rejuvenation and Urban Transformation (AMRUT) 2015

Mission focuses on improving the quality of life by providing building infrastructure. AMRUT aims to bridge the gap between the infrastructural necessities and their accessibility by directly linking their provision to the households.

\section{Smart City Mission 2015}

Objective of this mission was to empower cities socially, economically and technologically. "Smart cities" will be provided with basic amenities such as water, electricity, solid waste management, shelter, public transport, health and education along with technological connectivity and egovernance These selected cities, once developed cities would focus on sustainable development and become support system for the neighboring cities.

HRIDAY: National Heritage City Development and Augmentation Yojana: Started in 2015

The Mission envisions preserving and holistically developing the heritage cities of India. India is always famous for its rich culture and has earmarked itself globally as one of the leading spot for Cultural tourism. HRIDAY ensures to basically strengthen the infrastructure of these identified heritage cities

of India on four aspects; physical, institutional, economic and social.

\section{Corporate Sustainability or Corporate Social Responsibility (CSR)}

While all the government agencies try catering to the needs of the society through different policies and the guidelines, the companies act, 2013, tries to pitch the private sector in to further help in contributing to the well of the society, and nature. CSR is a voluntary mechanism by which companies with Net worth $\geq 500$ Crore (or) Turnover $\geq 1000$ Crore (or) Net profit $\geq 5$ Crore have to form a CSR Committee and formulate CSR Policies. Companies hold themselves to a set of legal, ethical, social and ecological standards. As per CSR Rule, it is necessary to spend atleast $2 \%$ of the average profit of three years on CSR activities.

\section{ANALYSIS RESULTS}

Many of the National Policies initiated at Central level did not effectively work at Local level. Each city is different in size, density, context and complexities. It cannot be gauged with the philosophy of "One size fits all". According to $22^{\text {nd }}$ Report of Standing Committee on Urban Development 2017-18, all flagship schemes that government promises will bring "Urban Renaissance" have used just $21 \%$ of the allocated funds. Strong lack of co-ordination between implementing agencies is the major drawback why these intended benefits of National policies are still not visible.

\begin{tabular}{|c|c|c|c|c|}
\hline \multicolumn{6}{|c|}{ Funds Allocated, Released \& Utilised By Urban Development Programmes } \\
\hline Scheme & Funds Allocated & Funds Released & Funds Utilised & FR vs FU\% \\
\hline AMRUT & 12447.19 & 8629.36 & 2480.43 & 28.74 \\
\hline HRIDAY & 700.00 & 247.15 & 33.59 & 13.59 \\
\hline Smart Cities & 10084.2 & 9943.22 & 182.62 & 1.83 \\
\hline Swachh Bharat & 7690.52 & 5847.92 & 2223.22 & 38.01 \\
\hline National Urban Livelihood & 2600.83 & 1514.85 & 850.34 & 56.13 \\
\hline Pradhan Mantri Awas Yojana & 15025.9 & 10011.89 & 2080.52 & 20.78 \\
\hline Total & 48548.64 & 36194.39 & 7850.72 & 21.6 \\
\hline
\end{tabular}

Source: Twenty second report of Standing Committee on Urban Development (2017-2018)

The two percent of profit in CSR, being dedicated for the social responsibility, have been taking different levels of social and environmental issues into considerations to cater at various levels of detail that one could look at. However, there are think tanks also trying to review and assess the quality of the output the corporate social responsibility is giving back to the society, which makes the process more formal and with very little or sometimes no loop holes for one to get away.

All the recent policies have holistic approach towards sustainable cities but most of them fail in the long run at implementation level.

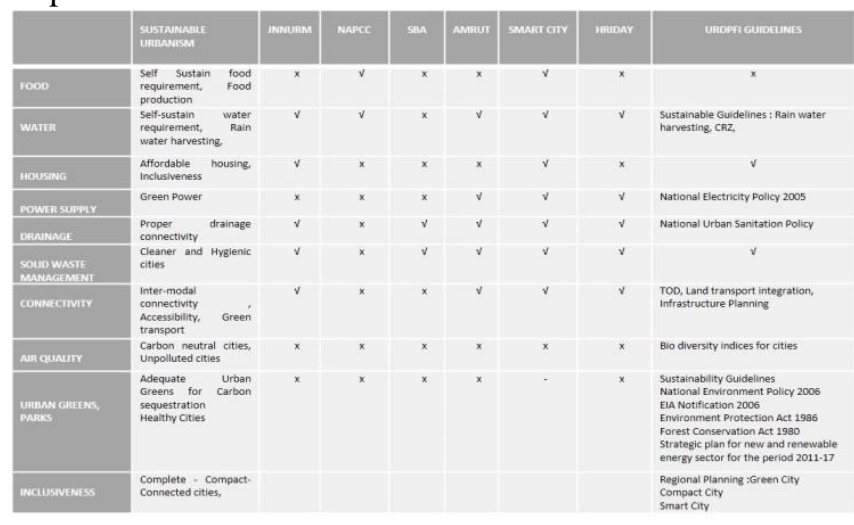

\section{CONCLUSION}

Reviews on different policies as done in this paper, not only gives clarity on what their impact lies on the larger perspective such as a nation like ours, but also helps economists and researchers help in understanding the ability of each of these policies and missions, and their areas of portray in their respective fields. All the Policies and Mission have taken a macro-level approach for cities where it focuses generally on providing basic amenities and infrastructure to people. Sustainable Urbanism on other hand should look into physical, social, economic and ecological well-being. Sustainable Urbanism is an interdisciplinary professional practice in urban planning / urban design where it relates to disciplines of Architecture, Landscape, Heritage, Civil and Environmental engineering along with allied disciplines like Humanities, Culture studies, Human Psychology, Health and Science etc. Sustainable Urbanism caters to People and City with both tangible and intangible development. Cities should be planned so as to create them Self- sustaining cities which is capable of sustaining their food requirement, sustain their 
energy requirement, sustain their air quality, sustain their water quality, and sustain their economic stability. Motivation of city expansion and engulfing the outskirts should be to make the city self-sustaining. Unplanned growth of cities is further complicating the issue creating Gated Cities. The gap created between Central Level initiated Missions and Polices and Comprehensive Development plan of cities needs to fill. Strategies like firmly working with large institutional integration with major institutions in the country shall help in adapting the right policy framework and also shall be more contextually concentrated when it is boiled down to a micro level of a particular ward level inside a planning district, through bottom-up approaches. Although sustainable city models depict car free or walkable cities, the density in Indian cities have forced the planners to design cities more for cars and less for people. With the growth rate of cities increasing so rapidly and lack of interaction between the rural bodies and urban areas, strategies like establishing a strong relationship between $73^{\text {rd }}$ amendment act and the $74^{\text {th }}$ amendment act could be a strong reinforcement for systematic developments.

Although the history of contemporary planning practices was in in early 1920, by the Bombay Improvement Trust act, the evolution of planning process has always been impacting the cities in a better way throughout the process. Introduction of URDPFI Guidelines in 2014 was a major step towards Urban sustainability but Indian cities still face numerous challenge in achieving overall sustainable development as these guidelines lacks the focus at micro level implementation. Planning need to adapt qualitative approach and livability in planning, focusing on concepts of inclusiveness, safe walkability, multi modal transport connectivity and urban greens. Current City planning focus on providing infrastructures such as educational institutions and healthcare for a set of population and density but it does not comprehend about the total green cover a city should have, so as to sequestrate the carbon footprint. Environmental, social and economic settings of cities influence human health and well-being. Urban planning thus plays an important role in shaping this. There is need for urban planners to integrate "Health and Sustainability" both at policy level and at implementation level for potential development and quality of life in cities. With emerging issues like lack of inclusive planning, sustainable habitat parameters, integration of land use and transport at planning stage, lacuna in urban reforms, creating service level benchmarks, plans like city sanitation plan, city drainage plan capital investment plan and financial operating plan, disaster management plan and comprehensive mobility plans can be made more effective using the URDPFI guidelines. There is need for greater bottom-up planning, capacity building and greater hand holding amongst urban and rural region. URDFI guidelines need to be much more than just guidelines but should act as implementing regulatory policies for urban planning.

\section{REFERENCES}

1. Airpocalypse: Assessment of Air Pollution in Indian Cities. Report, Greanpeace, www.greanpeace.org/india
2. Kidd, C.V. J Agric Environ Ethics (1992) 5: 1 https://doi.org/10.1007/BF01965413

3. Farr, Doughlas, Sustainable Urbanism: Deign with Nature ISBN-13: 978-0471777519

4. Galford, Chris (8 September 2017). "AEP Ohio to build car charging stations as part of Columbus Smart City initiative". Daily Energy Insider. Retrieved 25 September 2017

5. Creating Sustainable Environment : New Urbanism www.newurbanism.org

6. https://www.unenvironment.org/regions/asia-andpacific/regional-initiatives/supporting-resourceefficiency/sustainable-cities

7. India's Urban Awakening : Building inclusive cities, sustainable economic growth, McKinsey Report

8. All Acronyms. 2019. UIDSSMT - Urban Infrastructure Development Scheme for Small and Medium Town. Retrieved April 4, 2019, from https://www.allacronyms.com/UIDSSMT/Urban_Infras tructure_Development_Scheme_for_Small_and_Mediu m_Town

9. Stevens, Plowright, Adhya, Defining Sustainable Urbanism : towards a responsive urban design https://www.researchgate.net/publication/256079248

10. Steffan Lehmann, Sustainable urbanism: towards a framework for quality and optimal density? Lehmann Future Cities and Environment (2016) 2:8 DOI 10.1186/s40984-016-0021-3

11. Ministry of Housing and Urban Affairs, JNNURM, http://mohua.gov.in/cms/about-jnnurm.php

12. Ministry of Housing and Urban Affairs, AMRUT, http://mohua.gov.in/cms/amrut.php

13. National Action plan on Climate Change, http://envfor.nic.in/ccd-napcc

14. India Today Report, https://www.indiatoday.in/educationtoday/gk-current-affairs/story/8-missions-govt-napcc1375346-2018-10-25

15. Ministry of Housing and Urban Affairs, URDPFI http://mohua.gov.in/link/urdpfi-guidelines.php

16. Proptiger_guide/post/6-urban-development-schemes

17. Duhl, Sanchez, WHO Report, 1999, Healthy Cities and the City Planning Process: A background document on links between Health and Urban Planning

18. Batra, PRIA; Ignorance is not bliss! -How JNNURM failed in Small and Medium Cities https://www.pria.org/engagedcitizens-responsive-city/?p=935 